\title{
WEB TV Sebagai Media Alternatif Mengakses Informasi
}

\author{
Sri Handayani \\ (sri_hand@mti.ugm.ac.id) \\ Dosen Jurusan Teknik Informatika Universitas Semarang
}

\begin{abstract}
The Information Technologies are growing fast. One of them is Internet. There are various applications to share information offered in Internet. WebTV is one of them. WebTV is interactive television using Internet as its distribution media. WebTV can be watched all the time, both delay or direct broadcasting.There are some main benefits of WebTV compared with common television are: there are no competition in getting frequency, the consumers are not limited by time to watch their preferred programs, there is an interaction in internet in using such services as e-mail, chat, e-commerce, e-government, e-education, digital trend influences the compound of television and internet, One of the strategies used in television industry is increasing the brand image.
\end{abstract}

Keywords: Information technology, internet, Web TV

\section{Pendahuluan}

Definisi WebTV adalah untuk menampilkan siaran televisi interaktif dan biasa. Penerimaan siaran televisi ini, dapat dilakukan secara bersamaan pada saat kita mengakses internet termasuk mengunakan surat elektronik (email), dan chat online. Televisi interaktif atau WebTV, merupakan sebuah teknologi multimedia yang memanfaatkan internet sebagai media distribusi datanya. Perilaku konsumen disini dijadikan sebagai tolak ukur dalam menentukan pilihan program televisi yang akan disajikan. Dibandingkan televisi biasa, internet dapat menawarkan kombinasi interaktif antara konsumen dan produsen. Pengguna dapat mencari sendiri sesuai dengan seleranya untuk menentukan jenis siaran, baik siaran langsung maupun siaran tunda. Dan tidak terikat oleh program program televisi yang sudah ditetapkan oleh penyedia layanan televisi.

Masalah utama dari penerimaan Web TV di internet adalah kecepatan dan keaktualan informasi yang ada karena pengaruh delay yang terjadi selama akses berlangsung. Keaktualan informasi merupakan hal terpenting dalam era teknologi saat ini. Semakin aktual informasi yang diperoleh semakin tinggi nilai informasi yang dimiliki.

\section{Teknologi Televisi}

Sampai dengan awal tahun 1990 sedikitnya terdapat sembilan produk teknologi pertelevisian di dunia, yang digunakan sebagai media untuk menyampaikan informasi dan hiburan. Sembilan produk teknologi pertelevisian tersebut adalah :

- High Definition Video System : Merupakan kamera video yang dilengkapi dengan system editing dan mampu merekan serta mentransfer film cerita yang langsung disalurkan ke gedung-gedung bioskop. 
- Sistem Imax: Memberikan kesan seluruh penontonnya seolah-olah terlibat dalam cerita. Film dengan layar 70 $\mathrm{mm}$ memiliki rasio 20.5 : 30.5 .

- Sistem Diamond Vision : Sistem yang dapat memproyeksikan video signal pada layar lebar, dengan ukuran 5,4 m - 4,1 m, baik untuk siaran di luar maupun di dalam ruangan.

- Sistem Teletext : Merupakan surat kabar elektronik, yang isinya antara lain berita, ramalan cuaca, harga pasar serta pengumuman lain.

- Sistem Still Picture Broadcasting : Untuk keperluan pendidikan.

- Sistem Cable Television : Sistem ini juga disebut CATV (Community Antenna Television) Sinyal penyiarannya dilakukan secara khusus kepada para pelanggan melalui decoder, dengan menggunakan kabel atau pancaran satelit.

- Sistem Pay Television : Penyiarannya melalui sentral video, hanya untuk suatu tempat (hotel, terminal dan lain-lain) dengan cara membayar, memasukkan coin, apabila ingin menononnya.

- Sistem Siaran Satelit Langsung : Sistem ini disingkat DBS (Direct Broadcasting Satellite), yaitu dengan menggunakan antena parabola untuk menangkap siaran tersebut.
- Sistem High Definition Television (HDTV): Sistem pertelevisian yang ditemukan Jepang dengan aspek rasio 5 : 3 dan mempunyai scanning lines 1125 .

Selanjutnya penggunaan internet mulai mendominasi aspek pemerintahan, pendidikan, dan industri. Ada beberapa aplikasi atau layanan yang ada pada internet saat ini. Pada Januari 1992 didirikan suatu organisasi internet dengan nama internet society yang tugasnya menentukan aplikasi atau layanan apa saja yang ditawarkan internet. Pada awalnya, internet memiliki empat aplikasi utama yaitu:

1. Email yaitu aplikasi dengan kemampuan untuk membuat, mengirim dan menerima surat elektronik.

2. News yaitu suatu forum khusus yang dinamakan newsgroup, di mana user-nya memiliki hobi di bidang yang sama dan saling tukar-menukar informasi.

3. Remote Login dengan menggunakan program telnet.login. Pengguna dapat login (masuk) dan mengerjakan beberapa aktifitas di mesin lain.

4. File Transfer dengan menggunakan program FTP memungkinkan pengguna Internet untuk mengtransfer file antar mesin.

Selanjutnya aplikasi baru muncul yaitu World Wide Web (WWW). WWW memungkinkan pihak penyedia layanan untuk memberikan layanan kepada para pengguna internet dalam bentuk halamanhalaman informasi yang berisikan teks, gambar, suara dan bahkan video, yang dilengkapi juga dengan link untuk menghubungkan dengan halaman lain, atau ke mesin lainnya. Melalui media internet pula kini siaran televisi interaktif dapat diakses. Penerimaan siaran televisi ini, dapat dilakukan secara bersamaan pada saat kita mengakses internet termasuk mengunakan 
surat elektronik (email), dan chat online.

\section{Web TV}

Pada dasarnya web adalah sistem client-server. Di sini akan dijelaskan kedua bagian web yaitu bagian server dan client.

\section{- Sisi Client.}

Dari bagian pengguna, web merupakan kumpulan dokumen-dokumen yang tersebar di mesin-mesin di internet. Dokumen ini biasanya disebut page (halaman HTML). Tiap page mungkin mengandung link ke page yang lain di mesin yang lain di internet. Halaman web yang melakukan point ke halaman lain ini yang dinamakan hypertext. Teks string yang melakukan link ke halaman lain disebut hyperlink. Halamanhalaman web ini dapat dilihat menggunakan program yang dinamakan browser. Browser mengambil halaman yang diinginkan, melakukan interpretasi terhadap teks yang diperoleh, melakukan perintah yang ada pada page, dan menampilkan hasilnya pada monitor komputer. Halaman web yang berisikan audio track, video clips atau keduanya dinamakan hypermedia.

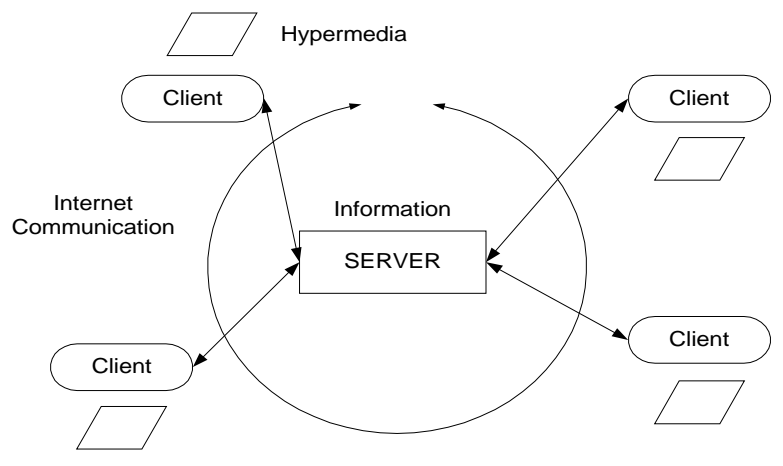

Gambar 1. Organisasi Teknis WEB

- Sisi Server.

Setiap situs web harus memiliki server yang selalu mendengarkan permintaan dari mesin port 80 TCP di Internet. Jika sebuah koneksi telah terbentuk, mesin client akan melakukan permintaan (request) dan server mengirimkan balasan permintaan. Protokol yang mendefinisikan request dan replies ini dinamakan HTTP (Hypertext Transfer Protocol).

Delay adalah jeda waktu antara proses penyiaran informasi dari stasiun $\mathrm{TV}$ dengan proses pengaksesan informasi melalui Web TV. Delay yang terjadi terdiri dari 3 jenis delay, yaitu: Delay propagasi, Delay Transmisi, dan Delay Pemrosesan.Delay propagasi adalah lama waktu perjalanan yang diperlukan untuk mengirimkan informasi di dalam sebuah saluran. Selain media transimisinya, teknologi yang digunakan sendiri juga berpengaruh terhadap delay propagasi. Delay transmisi adalah lama waktu yang diperlukan untuk meletakan sebuah informasi pada media transmisi yang digunakan. Delay transmisi ini dipengaruhi oleh kecepatan dan ukuran informasi. Delay pemrosesan adalah delay yang terjadi selama proses penyiaran informasi sampai dengan penerimaan informasi.

\section{Liputan 6}

Berikut ini salah satu stasiun WebTV yang diamati kinerjanya di internet: www.sctv.co.id. Stasiun WebTV SCTV (Surya Cipta Televisi), merupakan khusus siaran tunda dari perusahaan televisi di Indonesia, di mana menampilkan acara acara televisi SCTV. Acara - acara yang disajikan dalam bentuk streaming media, merupakan acara cuplikan dari siaran televisi sehingga pengguna dapat mengetahui sinopsis dari acara yang akan ditayangkan. 


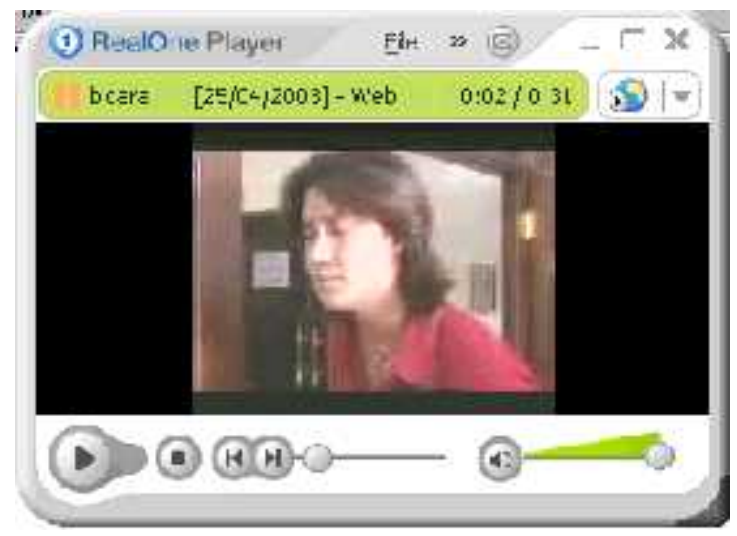

Gambar 2. WebTV www.sctv.co.id

Stasiun WebTV SCTV juga menyajikan berbagai berita/informasi berbagai bidang seperti sosial budaya, politik, olah raga. Bahwa program unggulan pada siaran televisi seperti Liputan6 Pagi, Buser (Buru Sergap), Potret. Namun semua siaran masih dalam bentuk siaran tunda.

Pelayanan informasi melalui WebTV merupakan strategi untuk menjangkau masyarakat melalui kanal akses. Kanal akses merupakan sarana atau fasilitas yang dipergunakan oleh masyarakat dalam menghubungkan dirinya (berinteraksi) dengan penyedia layanan televisi.

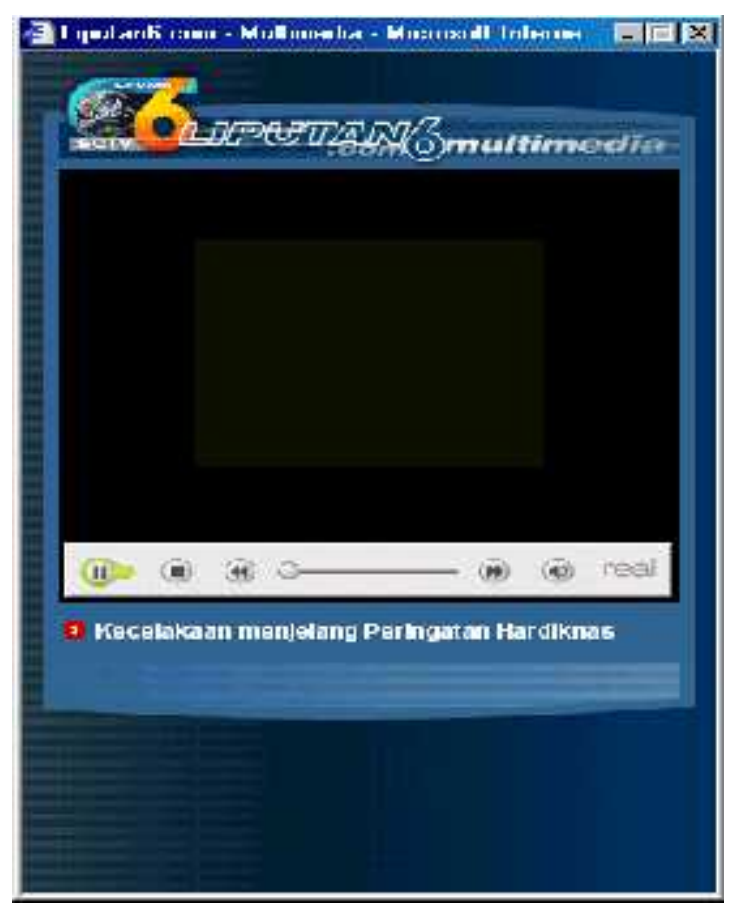

Gambar 3. Player WebTV www.liputan6.com

Melalui alat inilah berbagai interaksi dan transaksi dapat dilakukan. Namun masih banyak masyarakat Indonesia tidak mau mempergunakan teknologi modern seperti WebTV dan memilih mempergunakan teknologi yang lama (televisi), dengan alasan teknologi modern masih banyak permintaan yang harus dipenuhi seperti infrastruktur telekomunikasi, kualitas gambar, serta masih banyak masyarakat Indonesia belum mempergunakan teknologi internet.

Berdasarkan data dari APJII, pada tahun 2001, pelanggan di seluruh Indonesia sebanyak 1680000 orang, dan pengguna sebanyak 4200000 orang. Pelanggan Internet tersebut dibagi atas kategori perorangan, korporasi, serta komunitas pendidikan. Untuk kategori perorangan dibagi atas kelompok eksekutif yang menggunakan Internet untuk dirinya sendiri sekitar 100.000 orang. Kategori perorangan kelompok perumahan diperkirakan sebanyak 450.000 pelanggan yang masing-masing 
digunakan bersama-sama dengan anggota keluarga sehingga jumlah pengguna kategori ini diperkirakan 1,8 juta. Di Indonesia sendiri, pengguna secara umum adalah orang yang mempergunakan internet sebagai media informasi, sedangkan pelanggan ISP adalah orang yang berlanggan jasa internet dan mempergunakan internet sebagai media informasi.

Dari data statistik tersebut, perusahaan stasiun televisi yang mempergunakan WebTV sebagai alternatif siaran di Internet sangat cocok untuk memanfaatkan siaran tunda dengan fasilitas interaktif atau uji produk iklan atau menampilkan sinopsis siaran televisi dan film - film yang akan ditampilkan. Berikut ini akan ditampilkan pengguna dan pelanggan ISP (Internet Services Provider) Internet di Indonesia.

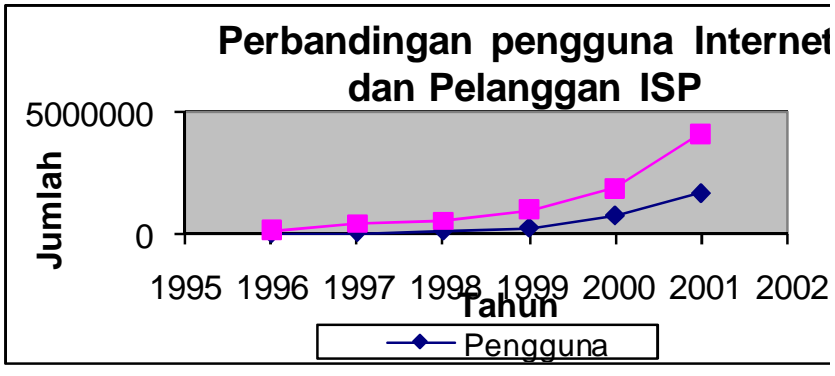

Grafik 1. Pelanggan ISP dan Pengguna Di Indonesia.

Dari polling majalah CHIP untuk pengguna WebTV, dengan banyaknya responden 500 peserta didapat sebanyak $85 \%$ responden menjawab akan menggunakan siaran tunda untuk menikmati siaran tersebut.

Seperti dijelaskan diatas, penguna dan pelanggan internet di Indonesia masih didominasi kalangan komunitas pendidikan dan perorangan serta perumahan. Prospek WebTV di Indonesia masih jauh dari harapan bila ditinjau dari pengguna dan pelanggan yang masih memiliki kebutuhan akses internet yang rendah. Dengan berbagai alasan seperti masalah bandwidth, masih merasa nyaman dengan televisi konvensional, atau masih banyak masyarakat Indonesia yang belum mengerti dan mengenal teknologi modern. Belum lagi dari penyediaan perangkat komputer, akses internet yang masih mahal. Syarat penerimaan terbaik sebuah WebTV adalah mempergunakan koneksi 14x modem, merupakan mimpi bagi $99 \%$ pemakai internet di Indonesia. Kelayakan implementasi WebTV di Indonesia akan efektif bila digunakan siaran tunda dengan menampilkan berbagai fasilitas yang terdapat di internet. Namun untuk menghubungkan televisi dengan internet sudah layak diterapkan, dengan pertimbangan konsep interaksi konsumen dan produser.

Perkembangan televisi di Indonesia yang menganut sistem open sky policy artinya setiap orang diijinkan untuk menerima siaran televisi dimanapun dia berada. Berdasarkan kebijakan tersebut sampai saat ini, di Indonesia memiliki 600.000 antena parabola yang berkembang setiap tahun. Karena di indonesia, siaran televisi yang menggunakan terestrial masih dibatasi di daerah kota - kota besar seperti Jakarta, Bandung, Semarang dan Surabaya. Sementara daerah yang masih belum dapat di jangkau seperti Kalimantan, Sulawesi, Papua dan Sumatra, konsumen mempergunakan antena parabola untuk menangkap siaran tersebut langsung diterima dari satelit palapa $\mathrm{C}$.

Bila ditinjau dari pengguna pesawat televisi di Indonesia, jumlah pada tahun 1992 diperkirakan terdapat 14 juta pesawat televisi yang jumlahnya meningkat dengan tajam dari tahun ke tahun.

Perkembangan TV kabel merupakan alternatif pilihan dalam menikmati televisi selain menggunakan televisi biasa dengan mempergunakan gelombang UHF. Jaringan 
televisi kabel lebih tajam segmen khalayaknya, lebih efisien manajemennya, lebih jelas gambarnya dan lebih banyak alternatif salurannya. Perkembangan TV kabel merupakan gelombang ketiga dalam sistem televisi. TV kabel merupakan gambaran televisi masa depan. Berkaitan dengan WebTV, TV kabel dapat dikembangkan menjadi televisi interaktif untuk berbagai keperluan seperti video text, video conference, bangking transactions. Video demand adalah kemungkinan penonton mengatur acara sendiri menu acara harian menonton televisi, yang sumbernya dari puluhan stasiun televisi di seluruh dunia dan perpustakaan video yang jumlahnya sampai puluhan ribu acara televisi.

Berkembangnya WebTV di Indonesia dipengaruhi berbagai faktor yang saling berkait yang dapat menciptakan sebuah interaksi. Interaksi tersebut terbentuk dari kebutuhan penguna informasi. Berikut ini aspek-aspek yang dapat mempengaruhi yang menjadi prospek kebutuhan sebuah WebTV.

1. Ekonomi.

Aspek ekonomi secara makro dan mikro menghasilkan sebuah inovasi untuk meningkatkan pendapatan serta citra perusahaan dan untuk dapat berinterkasi dengan pelanggan. WebTV di Indonesia secara ekonomi dapat menjadi layanan informasi bisnis yang relevan. Relevan ditinjau dari segi biaya operasional, segi keuntungan. Biaya operasional dimaksudkan adalah kegiatan-kegiatan yang untuk menghasilkan produk WebTV. Perusahaan televisi telah mendapat biaya operasional dari iklan, begitu juga WebTV dapat dibantu dengan dengan menciptakan iklan secara audio dan video streaming. Dengan teknologi 'PUSH CAT', informasi ditambahkan dapat ditampilkan dalam audio-stream dan video-stream. Sesuai jam tayangnya, iklan yang sesuai dengan isi program berupa teks, grafik, animasi, hyperlink. Di Indonesia masalah pengguna komputer sebagai alternatif menikmati siaran televisi pada internet terbentur dengan masalah punya dan tidak punya peralatan tersebut. Mayoritas pengguna internet di Indonesia banyak menggunakan televisi biasa untuk menikmati siaran tersebut. Sedangkan menikmati WebTV di Indonesia bertahap akan menjadi trend baru dalam mendapatkan informasi.

\section{Bandwidth.}

Aspek kebutuhan bandwidth adalah kebutuhan dasar dalam menyalurkan informasi yang akan disajikan dalam bentuk audio dan video streaming. WebTV di Indonesia direkomendasikan saat melakukan proses olah gambar dengan mempergunakan single rate atau mempergunakan kecepatan modem 28.8 Kbps. Ukuran frame, standar kompresi data, adalah sebagai faktor pendukung untuk membentuk video dan audio streaming. Kebutuhan bandwidth di Indonesia dapat dimanipulasi pada sisi proses editing file streaming. Dengan ukuran frame dan kompresi data yang disajikan menghasilkan distribusi penampilan gambar yang dapat dinikmati oleh konsumen.

3. Teknologi Kompresi Data.

Teknik kompresi data pada file streaming, memerlukan sebuah teknik yang dapat membawa audio dan video streaming sehingga pada saat user / konsumen menikmati WebTV, kualitas dan ketajaman gambar dapat dihasilkan maksimal dengan kondisi bandwidth di Indonesia. Teknik kompresi yang digunakan pada file streaming bisa berupa dari MPEG-4, DivX, atau RM (Real Media). Setiap file kompresi ini 
ditentukan juga besarnya frame sehingga menghasilkan kecepatan transfer audio dan video secara optimal pada jalur internet. Video yang ditampilkan tergantung dari tingkat ketajaman lensa pada pengambilan gambar. Kualitas gambar yang diambil dari file asli kemudian dikompresi dengan kompresi khusus untuk teknologi streaming yang artinya dapat supaya dapat informasi tersebut dapat dilewati melalui internet.

4. Perilaku pengguna.

Konsumen yang dapat menikmati WebTV di internet adalah kebanyakan tinggal di daerah perkotaan. Prilaku pengguna yang dimaksud adalah dalam kebiasaan menikmati siaran televisi. Bagi orang Indonesia, siaran televisi dapat diterima gratis dan hanya membeli pesawat televisi. Tanpa harus berlangganan siaran televisi. Walaupun kenyataanya operasional perusahaan televisi mendapatkan sumber pemasukan dari masyarakat melalui iklan produk dimana masyarakat membeli produk tersebut.

Perilaku konsumen dalam menikmati siaran WebTV ingin menyaksikan siaran tunda atau mengubah kebiasaan dalam menikmati siaran televisi. Trend ini pengguna WebTV ini dapat dijadikan sebagai sebuah perilaku konsumen untuk menjadikan internet sebagai media komunikasi yang interaktif antara perusahaan televisi dengan pelanggan ataupun dari pelanggan kepada kegiatan bisnis.

\section{Penutup}

1. Ada beberapa keunggulan utama WebTV dibanding dengan televisi biasa yaitu:

a. Tidak terjadinya perebutan frekuensi siaran. Karena keterbatasan ruang medium di udara untuk gelombang FM. Pada WebTV yang terjadi adalah proses download dan upload sebuah informasi. Sehingga proses penerimaan siaran terjadi pada jalur internet.

b. Konsumen tidak dibatasi waktu dalam menentukan sendiri sajian siaran yang ingin disaksikan.

c. Terjadi interaksi di internet dalam memanfaatkan layanan seperti e-mail, chat, e-commerce, e-government, e-education.

d. Trend digital mempengaruhi penggabungan televisi dengan internet.

d. Salah satu strategi perusahaan televisi dalam meningkatkan citra perusahaan.

2. Web TV menjadi sarana alternatif media akses informasi bagi kebanyakan rakyat Indonesia yang tinggal di perkotaan.

\section{DAFTAR PUSTAKA}

Darwanto. 2007. Televisi Sebagai Media Pendidikan. Jakarta. Pustaka Pelajar.

Purbo, W. Onno. 2005. Konferensi Video Melalui Internet. Yogyakarta: Penerbit Andi.

Majalah CHIP. 2004. Televisi di Internet 1000 Channel gratis. Jakarta. 